\title{
Sustainable tourism and management tools
}

\author{
S. Bimonte \\ Department of Political Economy, University of Siena, Italy
}

\begin{abstract}
This paper addresses the question of whether sustainable tourism is a balance between the environment, economy and community issues or whether it is up to the community to decide where the balance should lie. To answer such questions and produce a theoretical framework to select the appropriate economic instruments to deal with sustainability in tourism, it proposes an economic interpretation rooted in a property rights framework à la Coase. Moreover, considering the peculiarity of the sector, the paper argues that to implement the appropriate policies for sustainability in tourism, more than elsewhere, a simultaneous proper management of tourism demand and supply, and a set of instruments of a more non-technical than technical nature are required.
\end{abstract}

Keywords: sustainable tourism, technical and non-technical instruments, communities participation.

\section{Introduction}

The point we make in this paper is that in tourism we have to cope with problems that one does not encounter or that present themselves in a different way in other fields. Therefore, it argues that, although sustainable development and sustainable tourism may share some areas of mutual concern, the latter has its own specificities to be considered. These specificities need to be analyzed when selecting policies for sustainable development in tourism (Butler [1, 2]; Bramwell and Lane [3]; Hunter [4]; Sharpley [5]).

Because of its specificities, one of the main issues to be addressed when dealing with sustainability in tourism is "whether sustainable tourism is a process whereby balances should be struck between the environment, economy and community issues or whether it is up to the community to decide where the balance should lie" (Hardy et al [6], p.491). To answer such a question and produce a theoretical framework to select the appropriate economic instruments 
to deal with sustainability in tourism, the paper proposes an economic interpretation rooted in a property rights framework à la Coase.

Although within a traditional framework, some attention has recently been devoted to community consensus. However, although it grants some deeper insights into the issue, this approach fails to deal with the problem in its entirety and produce a sound understanding and proper management of tourism demand, which is still dealt with in terms of on-site management.

To the best of the author's knowledge, no-one has explored the issue in terms of static and dynamic efficiency, i.e. consensus as an efficient tool for seeking sustainability. To such an aim, a clear definition of "property rules" is required. This allows the implementation of simultaneous proper management of tourism demand and supply. The two sides have normally been considered and analyzed separately. We believe that whatever its definition, the development of sustainable tourism necessitates a balance of supply and demand in terms of needs, expectations, quality, quantity and, finally, price.

\section{About sustainability in tourism}

The debate on sustainable tourism has evolved (sometimes uncritically) from the wider debate on sustainable development (Sharpley [5]; Hunter and Green [8]; Butler [9]; an analysis of its historical evolution is presented in Hardy et al. [6]). The sustainability issue in tourism has often been analyzed and addressed within this same theoretical and methodological framework, the main concern being how to reconcile growth with the protection of the environment. This has brought some researchers to criticize the concept for its ecological and economic prejudice (Butler [2]; Farrell [10]; Cohen [11]), and to argue that although sustainable development and sustainable tourism may share some areas of mutual concern, the latter has its own specificities to be considered (Butler [2]; Hunter [4]).

The resources upon which tourism is based are of a built and/or natural type, tangible and/or intangible (Healy [12]). They are also specific in kind, including local cultures, norms, traditions, landscapes, products; to use Briassoulis' words, the place's genius loci (unique character) (Briassoulis [13]). It follows that, in the specific field of tourism, much more than in other fields, man is an integral part of the environment and cannot be demoted to a simple nuisance factor. Residents are one of the key elements to improving the appeal of a tourism destination, because of their contribution to producing the resources and the socalled hospitality atmosphere (Simmons [14]; Smith [15]). The host communities, where for community one intends the ecosystem (of which man is an integral part) and the relative baggage of matured norms that regulate the relationship between man and the environment, are themselves a locally defined and non-reproducible "tourism product", and play a fundamental role in utilizing and "producing" nature. This is why the communities are increasingly being viewed as a resource and as partners in sustainable tourism (Bramwell and Lane [3]; Ap [7]), and why the concept of "conservation" must evolve (and has, in fact, evolved) to identify the dynamic protection of biologic, cultural, ethnic, 
historic and productive diversities more than the sole conservation of biodiversity (Bimonte [16]).

In this context, local communities are simultaneously the means and the end to sustainability in tourism: the means, because any policy for the protection of the environment that denies human participation in its broadest sense (intended as a sense of belonging and both as participation in the decision-making process and as access to information and the wealth produced) has a greater chance of failing (Hitchcock et al., [17]; Uphoff and Langholz [18]; Bramwell [19]; Liu [20]); the end, because of the definition of community we gave above.

Therefore, the fundamental criteria that sustainability in tourism has to fulfil is to preserve the natural and socio-cultural capital of the host community, simultaneously satisfying the subjective and economic needs of both residents and tourists (Hardy et al [6]; Ko [37]; Hunter [21]; Farrell [10]; Butler [22]). Socioeconomic, environmental and cultural aspects, as well as subjective and qualitative aspects, therefore intermingle holistically in tourism.

Moreover, in many cases, the resources on which the tourism influxes rest are used simultaneously by both tourists and locals, often in different ways or for alternative purposes. Indeed, tourism is the encounter of two heterogeneous communities, the local and the tourist communities (which could actually be more than two, as they are not monolithic bodies - see the analysis carried out in Bimonte and Punzo [23]), each having different needs, interests, and expectations with regard to tourism resources (Hardy et al [6]; Williams [24]). A shared vision or common management regarding their use is therefore required to avoid locals entering into turbulent competition with tourists. Conflicts, in turn, reduce the quality of tourists' experience and, probably, their willingness to pay (WTP) (Bimonte and Punzo [23]). These aspects are exacerbated by the fact that most tourism resources share the characteristics of "public goods" and/or "common pool resources" (CPRs). In both cases an externality problem may arise, due to conflict or congestion, provoking a management issue.

In the absence of a universally shared definition that can constitute a framework to define actions, the concept of sustainability acquires the guise of a social convention, i.e. a body of objectives and principles regarding which maximum consensus must be achieved: an agreement among stakeholders to define shared rules. As a consequence, sustainability in tourism is both an equilibrium between contrasting needs and interests, where needs and interests, together with their bearers, are defined locally, and a balance between scientific principles, cultural traditions and institutional practices. Since scientific principles are uncertain, traditions, resources and institutions vary spatially and historically, and the perceived impact of many actions is subjective rather than objective and influenced by the prevailing social norms, it becomes clear that sustainability in tourism is a relative and evolving concept. This means that the problems to be faced, the way they are perceived and the shared principles of sustainability to be conformed to are completely different in the case of sensitive communities (for example, the communities of the Amazon) from those that we encounter in the case of a city rich in art or a crowded seaside resort situated in a populated and/or economically developed region (Shaw and Williams [25]). 


\section{The reference paradigms for sustainability in tourism}

It is now possible to address the question posed by Hardy et al [6] quoted in the introduction. The two implicit paradigms evoked by this question are stuck in two different reference frameworks: the liability as opposed to the property rules approach. This is not only a philosophical debate that requires resolution of the potentially conflicting concepts of an empowered community versus "balanced" decisions being made for the "greater good" (Hardy et al [6], p.491), but also a question of efficiency and efficacy.

The prerequisite for the first paradigm to be applied is a transcendent and unanimously accepted definition of sustainability, or at least an externally imposed decision. Unfortunately, the former does not exist and the latter, if not shared, could provoke conflicts and reactions. In fact, tourism is an interaction between a stable community of residents and a fluctuating population of visitors, wherein the former are the means and the end of sustainability and the latter are simultaneous users/consumers of resources partly produced by or historically belonging to the former. Therefore, both market and non-market relationships have to be considered and prospective conflict influencing the residents' welfare and the tourists' WTP, or even the very process of production of tourism resources, must be prevented (think of the Alarde case, Simonicca [26], or the sacred funeral ceremonies of the Toraja people, Robinson [27]).

According to what it has been said so far, we argue that sustainability in tourism is better addressed within a framework of property rules, where entitlement is allocated to the local community. In this view, it is a local community's prerogative to define norms and rules, at least with respect to some specific resources (Sen [28]), i.e. to decide where the balance should lie between the environment (in its broadest sense), economy and community issues. Moreover, sustainable tourists and/or tourism are unlikely without a sustainable local community (we consider all other stakeholders, such as tourist operators, public agencies etc., as being part of one of the two communities). Still, without a full understanding of the perception of tourism that those who live in, use and manage the resources have, there is a risk that sustainable tourism will not occur (Hardy and Beeton [29]).

In the property rules case the court has to specify the initial allocation of the entitlement, meaning that it decides which right is pre-eminent. Once this has been done, it merely has to prevent its violation. The injunction is removed only if and when the party entitled to the right consents to some degree of violation (Coase [30]) or to totally or partly transfer its entitlement to others. As it is easy to understand, in the absence of a clear initial allocation of the entitlement, it is de facto allocated to the party that can seize it more easily. There is factual evidence of such cases in developing as well as developed countries, where tourism development can be thrust upon marginalized cultural groups or upon subcomponents of group of residents without their consent (Robinson [27]).

Once we accept this principle, feasible sustainability in tourism becomes the outcome of a human decision (a social contract) delimitated by a spatialtemporal scale and aimed at selecting specific characteristics of the material and 
immaterial system to be preserved (Williams [24]) and the modalities of intervening on the causes of undesired changes (Manning [31]). Thus, the priority is to identify the environmental, cultural, and historic resources that one can and wishes to render enjoyable to the public, and their relative modalities of sharing and use. To such an end, an agreement is required regarding which resources to share and open up to the "interference" of tourism (front stage regions), in what form and under what conditions, and which resources, instead, should be set aside as inalienable spheres of life for the local communities (backstage regions) (see MacCallen [32]). According to the previous analysis, tourism is sustainable when it adapts to the locally defined set of norms (in the broadest sense of the term) or to norms defined elsewhere, to the extent that the latter do not clash with the former.

The risk in adhering to such a paradigm is that it may produce outcomes that do not conform to exogenous expectations, including the outright rejection of any tourism development. Moreover, as sustainability is an equilibrium between competing aspects, it follows that in reality, like any trade-off decisions taken on a day to day basis, it will almost certainly produce priorities which emerge to skew the destination area based tourism/environment system in favour of certain aspects (Hunter [21], p.859). This is consistent with the Coase theorem.

\section{Management schemes for sustainable tourism}

Proposition 1: If tourism is sustainable when it adapts to the locally defined set of norms (in the broadest sense of the term) or to norms defined elsewhere, to the extent that the latter do not clash with the former, then what is needed is a simultaneous proper management of tourism demand and supply.

Proposition 2: Since sustainability in tourism is a community based concept, and since communities, in the above meaning, are always the result of culture and institutions, sustainability evolves with norms and may be better addressed by modifying communities' reference values, that is by using mainly non-technical rather technical instruments.

The unsustainable use of resources is normally felt to be a consequence of market failure and, as such, it is supposed that the simple application of traditional economic analysis and instruments would cure it. Much of resource and environmental economics is about devising instruments and policies to promote a more efficient (sustainable) use of the environment.

The same happens in tourism. Here, the sustainability issues have been faced using technical instruments, largely within a framework of liability rule and demand management. To such an end, efforts have mainly been focused on sanctions, economic incentives (taxes or subsidies), management regimes (see, for example, Bramwell [19]), technological innovations, in order to reduce consumption of energy and resources, as well as legal prohibitions, as far as banning tourism in order to safeguard local culture.

Though useful and welcome in general, these technical armamentaria fall short of some specific themes that need to be dealt with in sustainable tourism. 
One of the most important themes is the importance of the qualitative dimension of many aspects, which forces us to create visitor management techniques capable of selecting or deselecting the "right" tourists and controlling and influencing their behaviour, rather than answering the question of how many are too many.

In fact, in many cases in tourism impacts need to be analyzed in terms of qualitative rather than quantitative changes, and the "impacting" sources are neither always well-defined nor uniform (the physical impact of a ton of $\mathrm{CO} 2$ is the same irrespective of its source whereas the impact of tourists depends on the typology of tourist). In these cases, rather than reducing the number of sources (for example tourists), one has to select and separate sources according to their behavioural patterns or modify their behaviour or perception of the problems. This could be a long-lasting and costly process because it entails a modification of reference values, because it requires a huge amount of (hidden) information to be gathered, and because non-point source forms of pollution demand a widespread and enforceable territorial control (just think of what is occurring in the forest in the Philippines, notwithstanding the ban).

Traditional instruments are not capable of achieving such an aim. Still, they perpetuate the bias of the tragedy of the commons (Williams [24]). They ignore contextual factors, such as history and culture, and overemphasize liability rules and property regimes as a tool to reduce the number of visits, to the exclusion of other factors (Brown and Harris [33]). Besides the above, traditional solutions also pose problems of equity (exclusion based on census, in the cases of prices/taxes) and/or efficient allocation of resources (numeric quota systems). In the case of quotas, it also violates the principle of methodological individualism so dear to the mainstream economic approach.

Therefore, since tourism development may be both supply-led and/or demand-driven (Liu [20]), and given our definition of sustainable tourism, the definition of shared rules that participation should aim for, and the consequent adjustment of the supply side to these rules become effective tools in developing sustainable tourism. In fact, the provision of tourist facilities and services that conform to such norms may contribute to stimulating and selecting coherent tourist demand. The sustainable development of tourism always necessitates a balance of supply and demand in terms of quantity as well as quality, expectations, willingness to pay and willingness to accept.

As an example, one may quote the case of the Amish and the case of the Palio of Siena. In both cases, sustainability refers to cultural rather than environmental aspects. Although different, both cases are examples of how a community may rely on the economic benefits of tourism while rejecting outside influence and preventing tourists from invading their private lifestyle, in the case of the Amish, and their public cultural event, in the case of the Palio of Siena. In both cases, tourists are welcome only if they conform to local shared norms.

Besides addressing qualitative and subjective aspects, and skipping the problems of equity and efficiency posed by traditional instruments, management of the supply side would also avoid the entitlement problem and the violation of the principle of methodological individualism. Restructuring and adaptation of 
the supply side to the body of shared norms would, in fact, generate a process of auto-selection of tourists and activities, i.e. a system in which the supply would spontaneously create its own demand, a kind of qualitative Law of Say. A person who wishes to eat meat would never enter a vegetarian restaurant.

In order to achieve these results, however, a courageous choice in fundamental policies is required, together with a significant cultural and organizational leap. Technical tools may help at the very beginning, but they have to aim to generate a modification in the reference values, this being the ultimate objective.

There is a growing consensus that an understanding of communities is needed and non-technical policies have to be developed, with the aim of defining a correct sustainability policy scheme. According to Hardin, "a technical solution may be defined as one that requires a change only in the techniques of the natural sciences, demanding little or nothing in the way of change in human values or ideas of morality" (Hardin [34], p.112). Coherently, a non-technical solution occurs only when it generates changes in human values or beliefs.

What is then required is an intervention on preferences that would produce a different capacity for enjoyment. The variation of preferences would bring about a greater degree of satisfaction from the good - the tourist experience - itself and the outcome would be a greater willingness to pay. The utility of an individual can increase through a greater consumption of goods or through greater enjoyment deriving from the same amount of goods. The true output of economic processes is not a physical flow, but the enjoyment of life (GeorgescuRoegen [35]). Policies should, therefore, aim to develop tools of participation capable of increasing the capacity to enjoy things (capabilities improvement). Butler argues that educating all concerned with tourism [...] is still the best key to developing more sustainable tourism, and that in the long term it is probably the only solution that is likely to be broadly successful (Butler [22] quoted in Bramwell [19], p.374).

The consequence of the argument developed here is that, in pursuing sustainability as a social fact, a precise definition of sustainable tourism is less important than the process that aims to achieve it. In such a context, participation is relevant to create consensus on some defined objectives, but it is much more important as a process to trigger an evolution in norms to which the tourism system then conforms. Wherever possible, sharing becomes the tool for the general acceptance of norms that in turn permits the development of a crosscheck on resources, which is the only course to pursue for sustainability in the long run. Sharing introduces reputation effects and triggers evolution in norms. To such an end, participation has to be interpreted in a broad sense. It envisages a clear allocation of the entitlement to the local community, in all its component parts, which means the active involvement of locals in the planning and development of tourism. But, more than "simple" participation in the decision-making process and in the definition of appropriate policies, it requires wider social participation, meaning participation in the identification process (choices), access to information, and participation in the allocation of the wealth produced (equitable development): a wider meaning than envisaged by the local Agendas 21 and 
some researchers. An inclusive process of development prevents conflicts and aids the change in the preferences of individuals that is necessary in order to modify lifestyles and choices, i.e. to shift social preferences away from private toward public goods. It is more and more evident that shared rules, improvement in the conditions of poverty and better distribution of income and of entitlements all represent necessary conditions for the achievement of sustainability. The perception of any resource does not rely on its physical properties, but on a range of social, economic, technological and psychological factors. Resources are not, they become (Zimmerman [36], quoted in Liu [20], p.465). This confirms the need to recover the social dimension of many decisions.

\section{Conclusion}

The main point the paper developed is that it is up to the community to decide where the balance between the environment, economy and community issues should lie. To analyse this issue it proposed an economic interpretation rooted in a property rights framework $\grave{a}$ la Coase. It suggested that sustainability in tourism is a community based concept, where by community it is meant the ecosystem (of which man is an integral part) and the entire collection of norms that constitute its collective conscience. It argues that tourism is then sustainable when it adapts to the community and to the locally defined set of norms.

Being so, the paper highlights the inadequacy of the traditional armamentaria that the theory has developed to deal with the issue of sustainability in tourism. It asserts that, while they may certainly play a useful role in dealing with certain types of problems (mainly of quantitative or measurable types), they are inadequate when socio-cultural and qualitative aspects are at stake.

It suggests using non-technical instrument in order to cope with the specificity of the issues in the case of tourism. To such aim, it proposes a simultaneous proper management scheme of demand and supply. This implies that the host community has to define shared rules to which the guest community has to adapt. A sustainable host community is a prerequisite for the existence of sustainable tourism. An auto-selection process would then follow more easily. This would avoid some of the problems posed by the traditional in terms of equity and efficiency.

The paper prompts a holistic and integrated analysis of the problem and, with the aim of rendering the concept of sustainability operational and providing a reference theory for sustainability in tourism, it delivers a tool to be used in pursuing the concept.

\section{Acknowledgements}

Research for this paper has been carried out as part of a 'PRIN 2004' financed by MIUR, Italy. I would like to thank Norman Uphoff, Lionello Punzo, and Alessandro Simonicca for having read the paper and for their useful comments and suggestions. However, responsibility is entirely mine. 


\section{References}

[1] Butler, R.W., "Tourism: an evolutionary perspective". Tourism and sustainable development: monitoring, planning, management, ed. J.G. Nelson, R.W. Butler, and G. Wall, University of Waterloo Press, Waterloo, p. 27-43, 1993.

[2] Butler, R.W., Sustainable tourism: a state-of-the-art review. Tourism Geography, 1(1), pp. 7-25, 1999.

[3] Bramwell, B., and Lane, B., Sustainable tourism: an evolving global approach. Journal of Sustainable Tourism, 1(1), pp. 1-5, 1993.

[4] Hunter, C., On the need to re-conceptualise sustainable tourism development. Journal of Sustainable Tourism, 3(3), 155-65, 1995.

[5] Sharpley, R., Tourism and sustainable development: Exploring the theoretical divide. Journal of Sustainable Tourism, 8 (1), 1-19, 2000.

[6] Hardy A.L., Beeton, R.J.S., and Pearson, L., Sustainable tourism: an overview of the concept and its position in relation to conceptualizations of tourism. Journal of Sustainable Tourism, 10(6), pp. 475-96, 2002.

[7] Ap, J., Residents' perceptions on tourism impacts. Annals of Tourism Research, 19(4), 665-90, 1992.

[8] Hunter, C., and Green, H., Tourism and the environment: a sustainable relationship? London and New York, Routledge, 1995.

[9] Butler, R., Alternative tourism: pious hope or Trojan horse? Journal of Travel Research, 28, 40-45, 1990.

[10] Farrell, B.H., Conventional or sustainable tourism? No room for choice. Tourism Management 20(1), 3-6, 1999.

[11] Cohen, E., Authenticity, Equity and Sustainability in Tourism. Journal of sustainable tourism, Vol. 10, n. 4, pp. 267-276, 2002.

[12] Healy, R., The "Common Pool" Problem in Tourism Landscapes. Annals of Tourism Research, 21:596-611, 1994.

[13] Briassoulis, H., Sustainable tourism and the question of the commons. Annals of Tourism Research, 29(4), pp. 1065-1085, 2002.

[14] Simmons, D.G., Community participation in tourism planning. Tourism Management, 15(20), 98-108, 1994.

[15] Smith, S.L.J., The tourism product. Annals of Tourism Research, 21(3), pp.582-95, 1994.

[16] Bimonte, S., Partecipazione come strumento per la sostenibilità vista come fatto sociale. Turismo, sviluppo economico e sostenibilità: teoria e pratica, eds S., Bimonte e L.F., Punzo, Edizioni dell'Università di Siena, Protagon, Siena, 2003.

[17] Hitchcock, M., King, V.T. and Parnwell, M.J.G., Tourism in South-East Asia: introduction. Tourism in South-East Asia, eds. M. Hitchcock; V.T. King and M.J.G. Parnwell, Routledge, London pp.1-31, 1993.

[18] Uphoff, N., and J. Langholz, Incentives for Avoiding the Tragedy of the Commons. Environmental Conservation, 25:251-261, 1998. 
[19] Bramwell, B., Selecting policy instruments for sustainable tourism. Global tourism, ed W.F. Theobald, Butterworth Heinemann, Oxford, Burlington, pp. 361-379, 2003.

[20] Liu, Z., Sustainable tourism development: a critique. Journal of Sustainable Tourism, 11(6), pp. 459-75, 2003.

[21] Hunter, C., Sustainable tourism as an adaptive paradigm. Annals of Tourism Research, 4(4), pp. 850-67, 1997.

[22] Butler, R., Tourism, environment, and sustainable development. Environmental Conservation, 18(3), pp. 201-209, 1991.

[23] Bimonte, S. and Punzo, L.F., The evolutionary game between tourist and resident populations and Tourist Carrying Capacity. Proceedings of the 17th EAEPE Annual Conference, Bremen, Germany, November, 10-12, 2005 (forthcoming), 2006.

[24] Williams, D.R., Sustainability and public access to nature: contesting the right to roam. Journal of Sustainable Tourism, 9(5), pp. 361-71, 2001.

[25] Shaw, G., and Williams, A.M., Critical issues in tourism: a geographical perspective, Blackwell Publishers Ltd, 2002.

[26] Simonicca, A., Antropologia del turismo, NIS, Roma, 1997.

[27] Robinson, M., Collaboration and Cultural Consent: Refocusing Sustainable Tourism. Tourism Collaboration and Partnerships: Politics, Practice and Sustainability, eds B. Bramwell, and B. Lane, Channel View Publications, Clevedon, pp. 295-313, 2000.

[28] Sen, A., Development as Freedom, Oxford University Press, Oxford, 1999.

[29] Hardy A.L., and Beeton, R.J.S., Sustainable tourism or maintainable tourism: managing resources for more than average outcomes. Journal of Sustainable Tourism, 9(3), pp. 168-192, 2002.

[30] Coase, R., The problem of social cost. The Journal of Law and Economics, 3, pp. 1-44, 1960.

[31] Manning, T., Indicators of tourism sustainability. Tourism Management, 20(1), 3-6, 1999.

[32] MacCallen, D., The tourist: a new theory of the leisure class, Schocken, New York, 1976.

[33] Brown, G. and Harris, C.C., The U.S. forest services: toward the new resource management paradigm? Society and Natural Resources, 5, pp. 231-45, 1992.

[34] Hardin, G., The tragedy of commons. Economics of environment: selected readings, ed Stavins, R.N., Norton, New York and London, pp. 9-22, 2000.

[35] Georgescu-Roegen, N., The entropy law, Harvard University Press, Cambridge (Mass), 1971.

[36] Zimmerman, E.W., World Resources and Industries. New York: Harper and Row, 1951.

[37] Ko, J., Assessing Progress of Tourism Sustainability. Annals of Tourism Research, 28(4), pp. 817-820, 2001. 